\title{
The Influence of Information Technology on Patient-Physician Relationships
}

\author{
Michael Weiner, $M D, M P H,{ }^{1,2,3}$ Paul Biondich, $M D^{2,3,4}$ \\ ${ }^{1}$ Indiana University Center for Aging Research, Indianapolis, IN, USA; ${ }^{2}$ Regenstrief Institute Inc., Indianapolis, IN, USA; ${ }^{3}$ School of Medicine, \\ Indiana University, Indianapolis, IN, USA; ${ }^{4}$ Children's Health Services Research, Indiana University, Indianapolis, IN, USA.
}

Interpersonal relationships and information are intertwined as essential cornerstones of health care. Although information technology (IT) has done much to advance medicine, we are not even close to realizing its full potential. Indeed, issues related to mismanaging health information often undermine relationship-centered care. Information technology must be implemented in ways that preserve and uplift relationships in care, while accommodating major deficiencies in managing information and making medical decisions. Increased collaboration between experts in IT and relationship-centered care is needed, along with inclusion of relationship-based measures in informatics research.

DOI: $10.1111 / \mathrm{j} .1525-1497.2006 .00307 . x$

J GEN INTERN MED 2006; 21:S35-39.

In patient-physician relationships, both patients and physicians have responsibilities, are willing to negotiate, and gain something through their relationships and encounters. ${ }^{1}$ In relationship-centered care (RCC), physicians and patients work together in pursuing shared goals in health care, with attention to both illness and personal experiences. ${ }^{2}$ The relationship-centered approach "involves physicians understanding the patients' perspectives, being responsive to the needs of patients (and in some cases their families), and sharing treatment-relevant power with patients and their families." 3 Relationship-centered care includes reference not only to patient-physician relationships but to other patient-practitioner relationships and to relationships among clinicians working together to care for a patient. ${ }^{4}$ The development and maintenance of relationships in health care depend on effective flows of information, both objective or subjective, whether verbal, visual, emotional, or tactile. Exchanges of information between patients and health care providers may originate from myriad sources, including people, medical records, books, journals, the internet, and other mass media. We use the term "information technology" (IT) to refer to all tools and processes for storing, manipulating, and communicating information. Information technology can refer to something as simple as a facsimile machine or as complex as a paper or electronic health record system.

The authors have no conflicts of interest to report.

This article was presented at the Ninth Biennial Regenstrief Conference, Marshall, IN, on September 30, 2004.

Address correspondence and requests for reprints to Dr. Weiner: Indiana University Center for Aging Research, Regenstrief Institute, Inc., 1050 Wishard Blvd., 6th fl., Indianapolis, IN 46202-2872

(e-mail: mw@cogit.net).
At first glance, any role for IT in RCC may not be obvious. However, upon reflection, it is clear that technical and social elements of the clinical workplace depend on each other to a great extent. ${ }^{5,6}$ Figure 1 abstractly portrays the interplay between relationships and information flow pertaining to the collection of specific clinical data about an individual patient. The terms "negotiation," "clinical reasoning," and "therapeutic alliance" refer to the 3 phases of a typical clinical encounter. ${ }^{7}$ Information is collected, stored, and processed prior to treatment or another intervention. Collection of information can but need not always occur via a health professional's mediation. Narratives, paper-based questionnaires, and direct entry of data by patients are examples of nonmediated information. Interpersonal communication and relationships are critical for some forms of history-taking, as well as interpretation, discussion and medical decision making. In these ways, relationships and information are closely intertwined in health care. Indeed, we would argue that relationships and information have always served together as 2 essential cornerstones of medical care.

We know that relationships can facilitate understanding and enhance exchanges of information, but can information or IT influence relationships? We offer 2 complementary views of ways in which IT can influence RCC: as a facilitator and as a barrier.

\section{IT AS A FACILITATOR OF RCC}

Information technology is beginning to facilitate many relationships in health care. Clinicians and patients have unprecedented access to health-related information, including the country's bibliographic database of more than 12 million references to journal articles in the life sciences. ${ }^{8}$ Finding health information is one of the most common uses of the internet, ${ }^{9}$ and today's patients have become more active participants in the decision-making process, often educating themselves about available interventions related to their medical conditions prior to seeing their doctors. ${ }^{10}$ For example, they may bring new information about drugs, diagnosis, treatment, or ongoing clinical trials to the visit. ${ }^{11}$ This shared access by patients and clinicians to a common pool of evolving information about health often facilitates greater sharing of concepts, terminology, and approaches used in evaluation and management of disease. This effect is not universal, since advancing age, low education, and other factors have been linked to less use of IT by some groups of consumers. ${ }^{9,12}$

Advances in communication of specific clinical data can also help RCC. With "store-and-forward" technology, ${ }^{13}$ receipt and processing of information occur separately from creation and delivery. Information is first packaged, stored, and forwarded to a person or place, where it can be reviewed later. Asynchronous communication ${ }^{14,15}$ is a special case of storeand-forward methods that usually refers to transmitting personal messages between individuals or groups. The recipient

Accepted for publication September13, 2005 


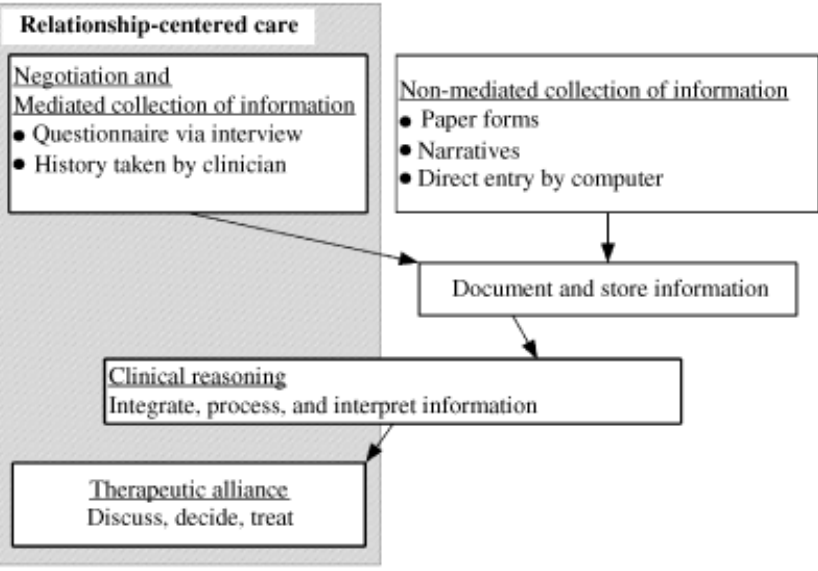

FIGURE 1. Interplay between relationships and flow of information. Information is collected, stored, and processed before treatment. Some methods of collecting and processing clinical information can be performed without relationships. Capitalizing on these possibilities can create efficiencies and higher yields for relationshipcentered care.

receives or processes a message after its time of creation. Paper-based letters, voice mail, and electronic mail (e-mail) are perhaps the most popular forms of asynchronous communication. E-mail and related forms of electronic asynchronous communication have provided new approaches to creating and maintaining relationships.

One could argue that written notes such as those generated by e-mail are a poor substitute for face-to-face encounters and create more ambiguity and opportunity for misinterpretation than direct dialogue. Others would add that RCC implies simultaneity of communication that is, by definition, not possible asynchronously. Several studies of e-mail in health care, however, indicate growing prevalence, acceptance, and desirability of asynchronous communication from both physicians and patients. ${ }^{16-18}$ In a recent study, 95\% of patients surveyed reported that e-mail was more efficient for patient-physician communication than using the telephone. ${ }^{19}$ Computer-based communication has proven especially useful-even better than synchronous communication-for patients interested in communicating about "sensitive" issues, ${ }^{19}$ such as substance abuse, ${ }^{20}$ because it lowers personal barriers and provides an outlet for deliberate, thoughtful expression that can enhance RCC. Although issues of privacy, ${ }^{21}$ security, access, ${ }^{17}$ litera$\mathrm{cy},{ }^{22}$ and e-mail overload remain, ${ }^{23}$ this form of IT promises to become a major aspect of conducting daily work in health care. As e-mail has facilitated dialogue and relationships in so many other areas of life-consider personal and family life, for example-so too it has the potential to enhance patient-physician relationships by linking individuals who might otherwise communicate less often or less efficiently. Fears about harms of such technologies are prevalent, but available evidence suggests that online advice rarely harms patients ${ }^{16}$ and should be used more liberally, when safe. Internet-based communications can now be secured using the Secure Sockets Layer, Secure HyperText Transfer Protocol, or related techniques. Guidelines for sharing medical information via the internet were developed and published years ago. ${ }^{21,24}$

Synchronous (real-time) communication, using live videoconferencing or networked relay chatting, also has the po- tential to bring together geographically separated individuals or groups. Adding video to audio can convey much unspoken information ${ }^{25}$ and provides new capabilities for remote or dangerous patients, such as prisoners or patients in rural areas with limited access to care, to communicate more efficiently with physicians. The video component can provide important nonverbal information and may serve to provide a closer simulation of a face-to-face encounter, compared with the telephone. Videoconferencing is increasingly being used and studied $^{26,27}$ but remains uncommon in daily clinical practice, partly because of limited reimbursement. Tactile, "virtual" information can also be relayed electronically from physicians to distant machines that can create intended movements. ${ }^{28}$

Gathering information is an essential component of effective communication in medical encounters, ${ }^{29}$ but it can also be tedious, rote, and time-consuming. ${ }^{30}$ Gathering information does not necessarily build relationships but with background information collected electronically, for example, could facilitate RCC through improved efficiencies and quality of time spent face-to-face. $\mathrm{We}^{31}$ and others ${ }^{20,32-35}$ have begun to develop systems that allow patients to enter their own clinical data directly into computer systems, using tools designed for automation and integration. This direct data entry may foster $\mathrm{RCC}$, by improving the integrity of the data and by providing time for patients and their clinicians to develop dialogue based on findings, rather than dialogue used simply for documentation.

Depending on the setting, IT can also facilitate self-management of disease, through 2-way exchanges of information that includes education and/or counseling. Patients who can generate parts of their own medical records may increasingly initiate medical discussions and actively engage their physicians in collaborative care. At the moment, direct data entry may not be an option for all patients, such as those with poor vision, low health literacy, or lack of experience with computers. Costs of IT are high, ${ }^{36}$ and most health institutions in the U.S. have not yet adopted comprehensive electronic medical record systems, ${ }^{37}$ but this is changing rapidly with new incentives and initiatives. ${ }^{38,39}$ Also, even with access to IT, patients and physicians do not always speak the same language. Systems that provide these forms of IT will require more research and development to be useful.

\section{IT AS A BARRIER TO RCC}

Despite much promise, the IT that is used to manage the wealth of medical information is inadequate. President George W. Bush remarked, “. . . our doctors and nurses have to manage 21 st century medical technology and complex medical information with 19th century tools." 40 For example, longitudinal clinical data exist without useful systems for identifying and tracking risk factors in real time. Computers that print nicely formatted pages get faxed to people who once again type the information into computers. There are elaborate systems for managing pharmacy benefits but few comprehensive systems to link prescribing with insurers' formularies. ${ }^{41}$ Electronic medical records have been established that seem to serve everyone except the patient and the physician, ${ }^{42}$ as physicians are required to spend more time entering data manually but have few tools for automating manipulation or interpretation of the same data. Our enhanced capacity to collect ever-larger volumes of historical and diagnostic medical 
information from our patients leaves us sorting and analyzing these data manually. Nurses and physicians report major difficulties with obtaining clinical information in a timely manner, ${ }^{43}$ and clinicians no longer have sufficient time in the day to manage both patients and their clinical data. ${ }^{44-46}$

Poorly integrated, poorly designed, and not fully realized IT has real, adverse effects for patients. Given a physician's fixed and finite resources, "bad IT" takes away time from otherwise potentially productive RCC, and primary-care physicians who spend less time with patients-and perhaps more time as data-entry clerks-are also more likely to experience malpractice claims. ${ }^{47}$ Many primarycare physicians have become less satisfied with their work, ${ }^{48}$ and physicians overall are more likely to consider early retirement. ${ }^{49}$ Medical complexity, interpersonal challenges, and administrative burdens have been cited as chief barriers to care of ${ }^{50}$ and communication with ${ }^{51}$ patients. Quality of care has been compromised: adherence to well-established clinical guidelines for preventive care and treatment of common and serious diseases is far from ideal, ${ }^{52}$ and many efforts aimed at changing physicians' behaviors have failed. ${ }^{53}$ Although Internists spend more than 1 hour per day managing test results, $83 \%$ have reported at least 1 delay in reviewing results, and more than half were dissatisfied with how they managed the results. ${ }^{54}$ Often, as a result of technology-based failings and distractions like these, many patients have concerns that are not discussed ${ }^{55-57}$ or expectations that are not met. ${ }^{58,59}$

In addition to accurate collection, storage, and processing of data, providing security and proper authorization for access to records is critical and needs improved speed, affordability, and validity. Successful relationship-centered care requires trust, ${ }^{60}$ and an untrustworthy system can interfere with trust in relationships. Failures can be projected onto the physician, to the detriment of the patient-physician relationship. Biological traits such as fingerprints, which are unique, can provide the greatest validity and efficiency of identification. Biometrics-based devices, which identify individuals based on biological traits, have been available for years but are underused in health institutions. Examples are iris scanners and fingerprint readers, many of which are now widely available at low cost.

Why has the quality of many patients' interactions with their primary-care physicians declined in recent years? ${ }^{61}$ Our theory is depicted in Figure 2. Although it may stem from inadequate empathy and communication skills, we postulate that medical training and practice combined with inadequate tools and support for IT have fostered the mismanagement of health information. Physicians who are empathic and nurturing under ordinary circumstances may fail to provide RCC because of the external influences of the clinical practice environment. Over time, these negative influences, marked by inefficiency, work overload, and inadequate IT, are actually reinforced. Although the theory remains to be tested, we vigorously argue that chief difficulties in fulfilling RCC are not caused by managed care, a lax new generation of physicians, or irrational clinical guidelines. ${ }^{62}$ We predict that careful examination of the dynamics will show that these breakdowns are due more to failures of managing information than anything else. They stem from the expected, natural inabilities of physicians to organize and apply the vast array of information that demands to be tamed. ${ }^{62}$ Along the way, the increasing complexity of health systems and IT's failure to provide effec-

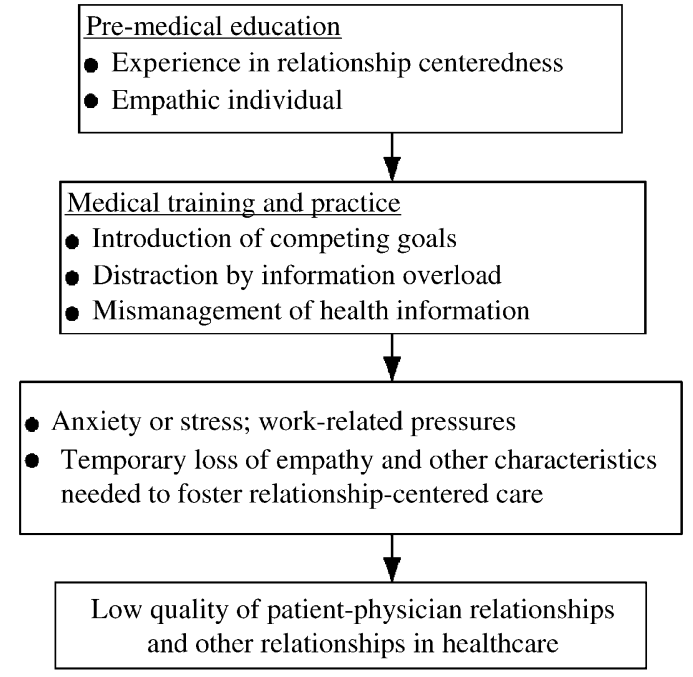

FIGURE 2. Theory of how medical training and practice influence relationships. Although low quality of patient-physician relationships may stem from inadequate empathy and communications skills, we postulate that medical training and practice has often led to this state, through introducing competing goals and fostering the mismanagement of health information.

tive management of medical care have adversely affected the patient-physician relationship.

Many of the tools that are needed to fix the largest systems-based barriers to effective patient-physician relationships have already been invented but remain inadequately integrated into clinical workflow. Information technology in health care can and will improve. Patients increasingly seek partnerships, ${ }^{63}$ and wish to share data and technology ${ }^{64}$ with their physicians. However, the problem of providing shared access to information has not yet been fully solved. Imagine a day when IT can intervene against adverse, task-oriented effects, to improve organization and facilitate flow of information exactly where and when it is needed. Implementation of IT has the promise of making it easier for health care professionals to do the right thing. Like a stethoscope in some ways, IT is a tool that can be used to improve health care, but as so few IT applications are truly developed by users, clinicians must be vocal and make developers and policy makers aware of exactly what they need.

Preventing failures of patient-physician relationships requires many changes. Fewer distractions and more time, ${ }^{65}$ "attending fully to the patient," occur for many clinical decisions and treatments, such as assessing contraindications to drugs, providing education to patients, and generating treatment plans for preventive care. These types of tasks are partly clerical, may not truly require a physician's individual decision and approval, and could potentially have an IT solution. Such principles, while threatening to some, could also improve patient safety and enhance RCC by focusing on people-oriented activities, such as personal engagement.

What else do we need to do now? Despite many advances and studies in health care IT, little work has been performed to study the direct influence of IT on patient-physician relationships. A recent, major, international conference dedicated entirely to communication in health care included 25 podium sessions $^{67}$ and 26 workshops, and not 1 of these sessions fo- 
cused on the role of IT in health care communication. New work is needed to address the interplay of IT and RCC, even beyond established research in human factors and personmachine interactions. We propose a research agenda dedicated to this area, to understand in more detail the ways in which IT influences RCC. This work will require increased attention to and inclusion of relationship-based measures in informatics research. For example, studies of new IT implementations should include measures of impact on relationships. Making IT part of the solution to our health-systems woes will also require increased collaboration between experts in IT and human relationships.

Physicians and patients will require education about how IT can influence their relationships and health care in general. A recent study revealed that physicians who use computers in examination rooms are less likely to make eye contact with patients. ${ }^{55}$ Findings like these will suggest new ways in which IT can be redesigned or molded in ways to facilitate, rather than hinder, health care and RCC. Clinicians may also require special training to generate positive, rather than negative, effects of pluripotent IT.

\section{LIMITATIONS OF IT}

Seeking technological solutions to problems is attractive to many. ${ }^{64}$ At first glance, it seems that the capabilities of IT are limitless: IT systems can provide comfort by allowing expression of emotions, ${ }^{68}$ can provided tailored advice based on known risk factors, ${ }^{69-71}$ and can be designed to detect nonverbal activity such as sleep and silent movement. ${ }^{72}$ Nevertheless, like trying to specify all that the mind can do, we retain a strong sense that IT cannot embody all aspects of how people live and mutually influence one another. Patients' concerns often manifest themselves indirectly, through clues ${ }^{73}$ that require interpersonal as well as logical intelligence. Horowitz et al. ${ }^{74}$ assert that the patient-physician relationship is the most consistently reported and powerful determinant of physicians' satisfaction. Although IT can improve patients' safety and efficiency of care by aiding human cognition, using IT as a crutch for humanistic deficiencies such as lack of compassion, commitment, empathy, ${ }^{75-77}$ or togetherness, will yield disappointing results. Smart IT must accommodate, preserve, and uplift interpersonal relationships in health care.

We thank the following individuals for their helpful insights and suggestions: Richard M. Frankel, PhD, Thomas S. Inui, MD, Morris Collen, MD, Octo Barnett, MD, and Christopher M. Callahan, $M D$.

Support: Dr. Weiner is supported by grant 5K23AG02008802 from the National Institute on Aging.

\section{REFERENCES}

1. Quill TE. Partnerships in patient care: a contractual approach. Ann Intern Med. 1983;98:228-34.

2. Participants in the Bayer-Fetzer Conference on Physician-Patient Communication in Medical Education. Essential elements of communication in medical encounters: the Kalamazoo consensus statement. Acad Med. 2001;76:390-3.

3. Williams GC, Frankel RM, Campbell TL, Deci EL. Research on relationship-centered care and healthcare outcomes from the Rochester biopsychosocial program: a self-determination theory integration. Families, systems \& health. J Collab Fam HealthCare. 2000;18:79-90.

4. Malloch K, Sluyter D, Moore N. Relationship-centered care: achieving true value in healthcare. J Nurs Admin. 2000;30:379-85.
5. Miller EA. The technical and interpersonal aspects of telemedicine: effects on doctor-patient communication. J Telemed Telecare. 2003;9:1-7.

6. Wears RL, Berg M. Computer technology and clinical work: still waiting for Godot. JAMA. 2005;293:1261-3.

7. Brock CD, Salinsky JV. Empathy: an essential skill for understanding the physician-patient relationship in clinical practice. Fam Med. 1993;25:245-8.

8. National Library of Medicine. Fact Sheet: MEDLINE. Available at: http://www.nlm.nih.gov/pubs/factsheets/medline.html. Accessed 15 December 2004.

9. Pew Internet \& American Life Project. Health information online. Available at: http://www.pewinternet.org/pdfs/PIP_Healthtopics_May05. pdf. Accessed 30 June 2005.

10. Diaz JA, Griffith RA, Ng JJ, Reinert SE, Friedmann PD, Moulton AW. Patients' use of the internet for medical information. J Gen Intern Med. 2002; 17:180-5.

11. Ford $\mathbf{P}$. Is the internet changing the relationship between consumers and practitioners? J Healthcare Qual. 2000;22:41-3.

12. UCLA Center for Communication Policy. The UCLA Internet Report"Surveying the Digital Future", Year Three. Available at: http://www.digitalcenter.org/pdf/InternetReportYearThree.pdf. Accessed 30 June 2005.

13. Houston MS, Myers JD, Levens SP, et al. Clinical consultations using store-and-forward telemedicine technology. Mayo Clin Proc. 1999;74: 764-9.

14. Kane B, Sands DZ. Guidelines for the clinical use of electronic mail with patients. J Am Med Inform Assoc. 1998;5:104-11.

15. Wilson Ev. Asynchronous health care communication. Commun ACM. 2003;46:79-84.

16. Ferguson T, Frydman G. The first generation of e-patients. BMJ. 2004;328:1148-9.

17. Mandl KD, Feit S, Pena BM, Kohane IS. Growth and determinants of access in patient e-mail and internet use. Arch Pediatr Adolesc Med. 2000;154:508-11.

18. Balas EA, Jaffrey F, Kuperman GJ, et al. Electronic communication with patients. Evaluation of distance medicine technology. JAMA. 1997; 278:152-9.

19. Houston TK, Sands DZ, Jenckes MW, Ford DE. Experiences of patients who were early adopters of electronic communication with their physician: satisfaction, benefits, and concerns. Am J Manag Care. 2004; 10:601-8.

20. Webb PM, Zimet GD, Fortenberry JD, Blythe MJ. Comparability of a computer-assisted versus written method for collecting health behavior information from adolescent patients. J Adolescent Health. 1999;24: 383-8.

21. Kane B, Sands DZ. Guidelines for the clinical use of electronic mail with patients. The AMIA internet working group, task force on guidelines for the use of clinic-patient electronic mail. J Am Med Inform Assoc. 1998; 5:104-11.

22. Katz SJ, Nissan N, Moyer CA. Crossing the digital divide: evaluating online communication between patients and their providers. Am J Manag Care. 2004; 10:593-8.

23. Katz SJ, Moyer CA. The emerging role of online communication between patients and their providers. J Gen Intern Med. 2004;19:978-83.

24. Rind DM, Kohane IS, Szolovits P, Safran C, Chueh HC, Barnett GO. Maintaining the confidentiality of medical records shared over the internet and the world wide web. Ann Intern Med. 1997;127:138-41.

25. Moore GT, Willemain TR, Bonanno R, Clark WD, Martin AR, Mogielnicki RP. Comparison of television and telephone for remote medical consultation. N Engl J Med. 1975;292:729-32.

26. Weiner M, Schadow G, Lindbergh D, et al. Clinicians' and patients' experiences and satisfaction with unscheduled, nighttime, internet-based video conferencing for assessing acute medical problems in a nursing facility. Proc AMIA Symp. 2003;709-13.

27. Telemedicine: an overview. Health Devices. 1999;28:88-103.

28. Eadie LH, Seifalian AM, Davidson BR. Telemedicine in surgery. Br $\mathrm{J}$ Surg. 2003;90:647-58.

29. Makoul G. Essential elements of communication in medical encounters: the Kalamazoo consensus statement. Acad Med. 2001;76:390-3.

30. Walsh SH. The clinician's perspective on electronic health records and how they can affect patient care. BMJ. 2004;328:1184-7.

31. Biondich PG, Anand V, Downs SM, McDonald CJ. Using adaptive turnaround documents to electronically acquire structured data in clinical settings. Proc AMIA Symp. 2003;86-90. 
32. Kim MI, Johnson KB. Patient entry of information: evaluation of user interfaces. J Med Internet Res. 2004;6:e13.

33. DeLeo JM, Pucino F, Calis KA, Crawford KW, Dorworth T, Gallelli JF. Patient-interactive computer system for obtaining medication histories. Am J Hosp Pharm. 1993;50:2348-52.

34. Porter SC, Silvia MT, Fleisher GR, Kohane IS, Homer CJ, Mandl KD. Parents as direct contributors to the medical record: validation of their electronic input. Ann Emerg Med. 2000;35:346-52.

35. Paperny DM, Hedberg VA. Computer-assisted health counselor visits: a low-cost model for comprehensive adolescent preventive services. Arch Pediatr Adolesc Med. 1999; 153:63-7.

36. Burton LC, Anderson GF, Kues IW. Using electronic health records to help coordinate care. Milbank Q. 2004;82:457-81.

37. Poon EG, Blumenthal D, Jaggi T, Honour MM, Bates DW, Kaushal R. Overcoming barriers to adopting and implementing computerized physician order entry systems in U.S. hospitals. Health Aff (Millwood). 2004; 23:184-90.

38. Chin T. Gingrich's grand vision, American Medical News. August 9, 2004:19-20.

39. Chin T. Hospitals are laying groundwork for EMRs, American Medical News. August 9, 2004: 27.

40. Bush GW. Transforming health care: the President's Health Information Technology Plan. Available at: http://www.whitehouse.gov/infocus/ technology/economic_policy200404/chap3.html. Accessed 15 December 2004.

41. Weiner M. State initiatives to control Medicaid drug costs. N Engl J Med. 2004;350:1912.

42. Weiner M, Gress T, Thiemann DR, et al. Contrasting views of physicians and nurses about an inpatient computer-based provider orderentry system. J Am Med Inform Assoc. 1999;6:234-44.

43. McKnight L, Stetson PD, Bakken S, Curran C, Cimino JJ. Perceived information needs and communication difficulties of inpatient physicians and nurses. J Am Med Inform Assoc. 2002;9(Nov-Dec suppl):S64-9.

44. Cabana MD, Rand CS, Powe NR, et al. Why don't physicians follow clinical practice guidelines? A framework for improvement. JAMA. 1999; 282:1458-65.

45. Cheng TL, DeWitt TG, Savageau JA, O'Connor KG. Determinants of counseling in primary care pediatric practice: physician attitudes about time, money, and health issues. Arch Pediatr Adolesc Med. 1999;153: 629-35.

46. Yarnall KS, Pollak KI, Ostbye T, Krause KM, Michener JL. Primary care: is there enough time for prevention? Am J Public Health. 2003;93: $635-41$.

47. Levinson W, Roter DL, Mullooly JP, Dull VT, Frankel RM. Physicianpatient communication. The relationship with malpractice claims among primary care physicians and surgeons. JAMA. 1997;277:553-9.

48. Landon BE, Aseltine R Jr., Shaul JA, Miller Y, Auerbach BA, Cleary PD. Evolving dissatisfaction among primary care physicians. Am J Manag Care. 2002;8:890-901.

49. Greene J. Physicians enticed into early retirement. Available at: http:// www.ama-assn.org/amednews/2000/07/24/prl20724.htm. Accessed 15 December 2004

50. Adams WL, Mcllvain HE, Lacy NL, et al. Primary care for elderly people: why do doctors find it so hard? Gerontologist. 2002;42:835-42.

51. Levinson W, Stiles WB, Inui TS, Engle R. Physician frustration in communicating with patients. Med Care. 1993;31:285-95.

52. Jencks SF, Cuerdon T, Burwen DR, et al. Quality of medical care delivered to Medicare beneficiaries: a profile at state and national levels. JAMA. 2000;284:1670-6.

53. Smith WR. Evidence for the effectiveness of techniques to change physician behavior. Chest. 2000;118:8S-17S

54. Poon EG, Gandhi TK, Sequist TD, Murff HJ, Karson AS, Bates DW. "I wish I had seen this test result earlier!" Dissatisfaction with test result management systems in primary care. Arch Intern Med. 2004;164: 2223-8.
55. Coiera E. Four rules for the reinvention of health care. BMJ. 2004:328: 1197-9.

56. Beckman HB, Frankel RM. The effect of physician behavior on the collection of data. Ann Intern Med. 1984;101:692-6.

57. Marvel MK, Epstein RM, Flowers K, Beckman HB. Soliciting the patient's agenda: have we improved? JAMA. 1999;281:283-7.

58. Kravitz RL, Callahan EJ, Paterniti D, Antonius D, Dunham M, Lewis CE. Prevalence and sources of patients' unmet expectations for care. Ann Intern Med. 1996;125:730-7.

59. Peck BM, Ubel PA, Roter DL, et al. Do unmet expectations for specific tests, referrals, and new medications reduce patients' satisfaction? J Gen Intern Med. 2004; 19:1080-7.

60. Thom DH, Hall MA, Pawlson LG. Measuring patients' trust in physicians when assessing quality of care. Health Aff (Millwood). 2004;23: $124-32$.

61. Montgomery JE, Irish JT, Wilson IB, et al. Primary care experiences of medicare beneficiaries, 1998 to 2000. J Gen Intern Med. 2004; 19:991-8.

62. McDonald CJ. Protocol-based computer reminders, the quality of care and the non-perfectability of man. N Engl J Med. 1976;295: 1351-5.

63. Roter DL, Stewart M, Putnam SM, Lipkin M Jr., Stiles W, Inui TS. Communication patterns of primary care physicians. JAMA. 1997;277: $350-6$.

64. Hofmann B. The myth of technology in health care. Sci Eng Ethics. 2002;8:17-29.

65. Murray A, Montgomery JE, Chang H, Rogers WH, Inui T, Safran DG. Doctor discontent. A comparison of physician satisfaction in different delivery system settings, 1986 and 1997. J Gen Intern Med. 2001;16: 451-9.

66. Inui TS. What are the sciences of relationship-centered primary care. $\mathrm{J}$ Fam Pract. 1996;42:171-7.

67. European Association for Communication in Healthcare. International Conference on Communication in Healthcare 2004: Parallel Sessions. Available at: http://www.each-conference.com/parallel.htm. Accessed 15 December 2004

68. Weizenbaum J. ELIZA - a computer program for the study of natural language communication between man and machine. Communi ACM. 1966:9:36-45.

69. McDonald CJ, Hui SL, Tierney WM. Effects of computer reminders for influenza vaccination on morbidity during influenza epidemics. MD Comput. 1992;9:304-12.

70. Dexter PR, Perkins S, Overhage JM, Maharry K, Kohler RB, McDonald CJ. A computerized reminder system to increase the use of preventive care for hospitalized patients. N Engl J Med. 2001;345: 965-70.

71. Shea S, DuMouchel W, Bahamonde L. A meta-analysis of 16 randomized controlled trials to evaluate computer-based clinical reminder systems for preventive care in the ambulatory setting. J Am Med Inform Assoc. 1996;3:399-409.

72. ADT Security Services I. QuietCare. Available at: http://www.adt.com/ resi/products_services/medical_alert_systems/quietcare/. Accessed 30 June 2005.

73. Suchman AL, Markakis K, Beckman HB, Frankel R. A model of empathic communication in the medical interview. JAMA. 1997;277: 678-82.

74. Horowitz CR, Suchman AL, Branch WT Jr., Frankel RM. What do doctors find meaningful about their work? Ann Intern Med. 2003;138: $772-5$.

75. Quill TE. Recognizing and adjusting to barriers in doctor-patient communication. Ann Intern Med. 1989;111:51-7.

76. Frankel RM. Emotion and the physician-patient relationship. Motivation Emotion. 1995;19:163-73.

77. Charon R. The patient-physician relationship. Narrative medicine: a model for empathy, reflection, profession, and trust. JAMA. 2001;286: 1897-902. 